Chinese Journal of Electronics

Vol.25, No.2, Mar. 2016

\title{
A Fault Diagnosis Method of Power Systems Based on an Improved Adaptive Fuzzy Spiking Neural P Systems and PSO Algorithms*
}

\author{
WANG Jun ${ }^{1,2}$, PENG Hong ${ }^{3}$, TU Min ${ }^{4}$, Pérez-Jiménez J. Mario ${ }^{5}$ and SHI Peng 6 \\ (1. School of Electrical and Information Engineering, Xihua University, Chengdu 610039, China) \\ (2. Sichuan Province Key Laboratory of Power Electronics Energy-saving Technologies and Equipment, \\ Chengdu 610039, China) \\ (3. Center for Radio Administration and Technology Development, Xihua University, Chengdu 610039, China) \\ (4. Neijiang Power Supply Company, Neijiang 641003, China) \\ (5. Department of Computer Science and Artificial Intelligence, University of Seville, Sevilla 41012, Spain) \\ (6. School of Electrical and Electronic Engineering, the University of Adelaide, SA 5005, Australia)
}

\begin{abstract}
A new fault diagnosis method based on improved Adaptive fuzzy spiking neural $P$ systems (in short, AFSN P systems) and Particle swarm optimization (PSO) algorithm is presented to improve the efficiency and accuracy of diagnosis for power systems in this paper. AFSN $P$ systems are a novel kind of computing models with parallel computing and learning ability. Based on our previous works, this paper focuses on AFSN P systems inference algorithms and learning algorithms and builds the fault diagnosis model using improved AFSN P systems for diagnosing effectively. The process of diagnosis based on AFSN P systems is expressed by matrix successfully to improve the rate of diagnosis eminently. Furthermore, particle swarm optimization algorithm is introduced into the learning algorithm of AFSN P systems, thus the convergence speed of diagnosis has a big progress. An example of 4-node system is given to verify the effectiveness of this method. Compared with the existing methods, this method has faster diagnosis speed, higher accuracy and strong ability to adapt to the grid topology changes.
\end{abstract}

Key words - Fault diagnosis, Power systems, Member Computing, AFSN P systems, Particle swarm optimization algorithm.

\section{Introduction}

With the continuous development of national economy, people's requirement for power quality is highly increasing. Simultaneously, more and more automatic devices are applied to power systems with the unceasing expansion of grid. However, when the grid fails, these automatic devices will generate a lot of alarm information. Especially, the diagnosis work will be more difficult while complex faults or uncertainty factors occur. When protection relays and current breakers operate incorrectly and the action messages of protection relays and current breakers are lost or cause more serious mistakes because of signal patch, the SCADA system of dispatching center can not provide complete and correct alarm information. In this case, the validity of diagnosis will be poor and the power blackout will be caused more severely. Therefore, it is very important significance to research an excellent fault diagnosis system for dealing with the uncertainty of action messages about protective relays and breakers.

Up to now, a large number of diagnosis methods have been presented, such as expert system ${ }^{[1,2]}$, artificial neural networks $^{[3,4]}$, optimization algorithm ${ }^{[5]}$, fuzzy reasoning ${ }^{[6]}$ and so on. However, fault diagnosis method based on expert system has a bottleneck of knowledge acquisition, fault tolerance, maintenance difficult and is difficult to analyze online for power system. Fault diagnosis method based on neural network requires many samples to train, lack the ability to explain their own behavior and export results, and is difficult to model for large-scale network. In the meantime, it is difficult to establish reasonable mathematical models of transmission network using fault di-

*Manuscript Received Mar. 3, 2014; Accepted June 12, 2014. This work is supported by the National Natural Science Foundation of China (No.61170030, No.61472328), and Fund of Sichuan Provincial Department of Science and Technology (No.2013GZ0130).

(C) 2016 Chinese Institute of Electronics. DOI:10.1049/cje.2016.03.019 
agnosis method based on a variety of optimization algorithm. Moreover, for fault diagnosis method based on fuzzy theory, there is a difficult problem how to establish the right of fuzzy rules and membership functions.

Membrane computing (also known as $\mathrm{P}$ systems) is inspired by the structure and the functioning of the living cell as well as from the cooperation of cells in tissues, organs. In recent years, scholars have proposed various computing models of $\mathrm{P}$ systems according to the functions and features of the living cells and tissues, or the methods of computer and math. Currently, there have three categories of $\mathrm{P}$ systems: cell-like $\mathrm{P}$ systems, tissue-like $\mathrm{P}$ systems and neural-like $\mathrm{P}$ systems ${ }^{[7]}$. The applications of $\mathrm{P}$ systems are mainly reflected in dealing with the complex and difficult problems of biology, and the classification and scheduling problems of computer science, and computer graphics. Some scholars use P systems to design approximate optimization calculation in order to solve problems in practical applications. For example, Huang et al. ${ }^{[8]}$ applied membrane computing for multi-objective optimization in control system. In Ref.[9], a hybrid approach based on differential evolution and tissue membrane systems is employed in constrained manufacturing parameter optimization. In order to deal with the representation of fuzzy knowledge and complete fuzzy reasoning, several extended spiking neural $\mathrm{P}$ systems have been proposed by the authors of this paper in recent years ${ }^{[10,11]}$. Furthermore, fuzzy reasoning spiking neural $\mathrm{P}$ system is applied in fault diagnosis in Ref.[12].

Based on our previous works, AFSN P systems were applied to improve the effective of fault diagnosis of power systems in Ref.[13]. However, the reasoning rate is not high due to utilize the fuzzy reasoning algorithm step by step in the process of diagnosis. In the meantime, only four kinds of detected information of protective relays and circuit breakers are considered in Ref.[13] so that the considered cases are not quite sufficient. Moreover, the situation is not premeditated when the information provided by SCADA system is incomplete and superfluous information is offered simultaneously. The data results are not quite accurate and the efficiency of LMS learning algorithm is not enough high. For these reasons, a fault diagnosis model based on AFSN P systems is proposed in this paper. In the meantime, a transfer function is led into the model so that the diagnosis is more accurate. Moreover, the process of fault diagnosis based on AFSN P systems is represented by matrix to improve the diagnosis rate obviously. In addition, particle swarm optimization algorithm is introduced into the learning algorithm of AFSN P systems, thus the convergence speed of diagnosis has a big progress.

\section{The Improved AFSN P Systems}

In Ref.[14], Zeng et al. adopted matrix to present Spiking neural P systems (in short, SN P systems) so that the computation of SN P systems can be very convenient. Therefore, the improved AFSN $\mathrm{P}$ systems with matrix representation are presented in this Section. Furthermore, it introduces how the fuzzy reasoning algorithm of AFSN $\mathrm{P}$ systems can be represented by operations with matrices, and that is called matrix reasoning algorithm based on AFSN P systems.

\section{AFSN P systems-based model for weighted fuzzy production rules}

In this section, we briefly review the weighted fuzzy production rules and fuzzy reasoning based on AFSN P systems. More details about AFSN P systems can be found in Refs.[13,15].

AFSN $\mathrm{P}$ systems (of degree $m \geq 1$ ) is a construct of the form

$$
\Pi=\left(A, N_{p}, N_{r}, \text { syn }, I, O\right)
$$

where

1) $A=\{a\}$ is the singleton alphabet (the object $a$ is called spike).

2) $N_{p}=\left\{\sigma_{p 1}, \sigma_{p 2}, \cdots, \sigma_{p m}\right\}$ is called proposition neuron set, where proposition neuron $\sigma_{p i}$ expresses the $i$ th proposition in a set of weighted fuzzy production rules, $1 \leq i \leq m$.

3) $N_{r}=\left\{\sigma_{r 1}, \sigma_{r 2}, \cdots, \sigma_{r n}\right\}$ is called rule neuron set, where rule neuron $\sigma_{r j}$ expresses the $j$ th weighted fuzzy production rule, $1 \leq j \leq n$.

4) syn $\subseteq\left(N_{p} \times N_{r}\right) \cup\left(N_{r} \times N_{p}\right)$ indicates synapses between proposition neurons and rule neurons.

5) $I, O \in N_{p}$ are input neuron set and output neuron set, respectively.

The weighted fuzzy production rules are expressed as the following three types.

Type 1: if $p_{1}$ then $p_{2}$;

Type 2: if $p_{1}$ and $p_{2}$ and $\cdots$ and $p_{m}$ then $p_{m+1}$;

Type 3: if $p_{1}$ or $p_{2}$ or $\cdots$ or $p_{m}$ then $p_{m+1}$.

The three types of the weighted fuzzy production rules can be modeled by three types of AFSN P systems respectively, shown in Fig.1. According to dynamic firing mechanism of AFSN P systems, the three types of weighted fuzzy production rules with the fuzzy reasoning process can be described as follows. More details about AFSN P systems can be found in Ref.[15]. (a)

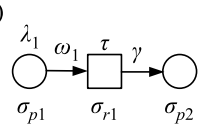

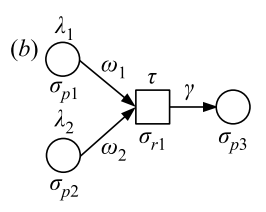

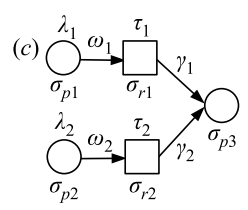

Fig. 1. Weighted fuzzy production rules expressed by the three types of AFSN P systems. (a) Type 1; (b) Type 2; (c) Type 3 
Type 1: $\alpha_{i+1}= \begin{cases}f_{\alpha}\left(\alpha_{i} \cdot \omega_{i}\right) \cdot \gamma_{j}, & \text { if } \alpha_{j} \geq \tau_{j} \\ 0, & \text { if } \alpha_{j}<\tau_{j}\end{cases}$

Type 2: $\alpha_{i+1}= \begin{cases}f_{\alpha}\left(\sum_{i=1}^{m} \alpha_{i} \cdot \omega_{i}\right) \cdot \gamma_{j}, & \text { if } \alpha_{j} \geq \tau_{j} \\ 0, & \text { if } \alpha_{j}<\tau_{j}\end{cases}$

Type 3: $\alpha_{i+1}= \begin{cases}\operatorname{MAX}\left(f_{\alpha}\left(\alpha_{i} \cdot \omega_{i}\right) \cdot \gamma_{j}\right), & \text { if } \alpha_{j} \geq \tau_{j} \\ 0, & \text { if } \alpha_{j}<\tau_{j}\end{cases}$

where $\alpha_{i} \in[0,1]$ is the fuzzy truth value of the proposition neuron $\sigma_{p i} . \alpha_{j} \in[0,1]$ is fuzzy truth value of the rule neuron $\sigma_{r j} . \omega_{i} \in[0,1]$ expresses the output weight of neuron $\sigma_{p i} \cdot \gamma_{j} \in[0,1]$ is called the certain factor. $\tau_{j} \in[0,1]$ is called the firing threshold. In Type $1, \alpha_{j}=\alpha_{i} \cdot \omega_{i}$. In Type $2, \alpha_{j}=\sum_{i=1}^{m} \alpha_{i} \cdot \omega_{i}$. In Type $3, \alpha_{j}=\alpha_{i} \cdot \omega_{i}$. Here $1 \leq i \leq m$ and $1 \leq j \leq n$.

2. The improved AFSN P systems with matrix representation

In this paper, reasoning algorithm of the improved AFSN $\mathrm{P}$ systems is different from that of AFSN $\mathrm{P}$ systems introduced above. A transfer function $f_{\alpha}(x)$ is added to rule neural to make the results more accurate. Firstly, three definitions are given as following.

Definition $1 \quad \boldsymbol{P}=\left(\alpha_{1}, \alpha_{2}, \cdots, \alpha_{m}\right)$ is proposition vectors, where $\alpha_{i}$ expresses fuzzy truth value of the proposition neuron $\sigma_{p i}, 1 \leq i \leq m$. Initial proposition vector is denoted by $P_{0}$.

Definition $2 \quad \boldsymbol{R}=\left(\alpha_{1}, \alpha_{2}, \cdots, \alpha_{n}\right)$ is called rule vectors, where $\alpha_{j}$ expresses fuzzy truth value of the rule neuron $\sigma_{r j}, 1 \leq j \leq n$.

Definition 3 Incidence matrix. The incidence matrix reflects the relationship between proposition neurons and rule neurons, and is denoted by $\boldsymbol{I} \boldsymbol{M}=\left[\omega_{i j}\right]_{m \times n}$ where the rows number of incidence matrix is the number of proposition neurons, and the columns number of incidence matrix is the number of rule neurons, and $\omega_{i j}$ indicates the weight between proposition neuron $i$ and rule neuron $j$.

Fig.2 is an example of AFSN $\mathrm{P}$ systems model. For Fig.2, the incidence matrix

is expressed as

$\boldsymbol{I} \boldsymbol{M}=\left(\begin{array}{cc}0.5 & 0 \\ 0.5 & 0 \\ 0 & 0.5 \\ 0 & 0.5 \\ -0.95 & -0.9\end{array}\right)$

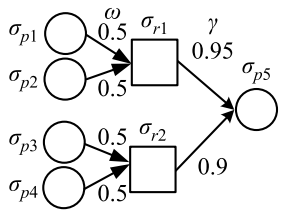

Fig. 2. An AFSN P systems model

The positive sign in $\boldsymbol{I} \boldsymbol{M}$ expresses the pointing to the rule neuron from proposition neuron. The negative sign in $\boldsymbol{I} \boldsymbol{M}$ expresses the pointing to the proposition neuron from rule neuron. $\omega_{i j}$ is the weight on the synapse if proposition neuron $i$ and rule neuron $j$ have connection. Otherwise, $\omega_{i j}=0$. In Fig.2, we assume that the fuzzy truth value of each proposition neuron is $\alpha_{p 1}=0.8564, \alpha_{p 2}=0.9833$, $\alpha_{p 3}=0.4, \alpha_{p 4}=0.75$, and the initial value of $\alpha_{p 5}$ is
0 , and $f_{\alpha}(x)=e^{-4.5(x-1)^{2}}$. Then $\alpha_{p 5}=0.92293$ via the fuzzy reasoning algorithm of AFSN P systems.

The reasoning process of AFSN P systems can be represented by the computing of matrix as follows.

$$
\begin{aligned}
& \boldsymbol{P}_{0}=(0.8564,0.9833,0.4,0.75,0) \\
& \boldsymbol{R}=f_{\alpha}\left(\boldsymbol{P}_{0} \cdot \boldsymbol{I} \boldsymbol{M}^{+}\right) \\
& =(0.8564,0.9833,0.4,0.75,0) \cdot\left(\begin{array}{cc}
0.5 & 0 \\
0.5 & 0 \\
0 & 0.5 \\
0 & 0.5 \\
0 & 0
\end{array}\right) \\
& =(0.9198,0.57) \\
& \boldsymbol{P}^{\prime}=\boldsymbol{R} \cdot\left(\boldsymbol{I} \boldsymbol{M}^{-}\right)^{\mathrm{T}} \\
& =(0.91985,0.57) \cdot\left(\begin{array}{ccccc}
0 & 0 & 0 & 0 & 0.95 \\
0 & 0 & 0 & 0 & 0.9
\end{array}\right) \\
& =(0,0,0,0,0.92293) \\
& \boldsymbol{P}_{1}=\boldsymbol{P}_{0}+\boldsymbol{P}^{\prime} \\
& =(0.8564,0.9833,0.4,0.75,0)+(0,0,0,0,0.92293) \\
& =(0.8564,0.9833,0.4,0.75,0.92293)
\end{aligned}
$$

Here, $\boldsymbol{I} \boldsymbol{M}^{+}$retains the positive elements in $\boldsymbol{I} \boldsymbol{M}$, and the negative elements in $\boldsymbol{I} \boldsymbol{M}$ are changed to zero. $\boldsymbol{I} \boldsymbol{M}^{-}$ retains the absolute values of negative elements in $\boldsymbol{I} \boldsymbol{M}$, and the positive elements in $\boldsymbol{I} \boldsymbol{M}$ are changed to zero. The basic step of matrix reasoning algorithm based on AFSN $\mathrm{P}$ systems is described as follows.

1) Compute the certain factors $\boldsymbol{R}=f_{\alpha}\left(\boldsymbol{P}_{0} \cdot \boldsymbol{I} \boldsymbol{M}^{+}\right)$ of rule neurons, that also is to implement the formula $f_{\alpha}\left(\sum_{i=1}^{m} a_{i} \cdot \omega_{i}\right)$.

2) Compare the certain factors of rule neurons with firing threshold $\tau$. If they are bigger than $\tau$, then the certain factors are reserved, else they are 0.

3) Calculate the certain factors of next proposition neurons, $\boldsymbol{P}^{\prime}=\boldsymbol{R} \cdot\left(\boldsymbol{I} \boldsymbol{M}^{-}\right)^{\mathrm{T}}$.

4) Count the certain factors of all the current proposition neurons, $\boldsymbol{P}_{1}=\boldsymbol{P}_{0}+\boldsymbol{P}^{\prime}$.

5) Replace the $\boldsymbol{P}_{0}$ in Step 1) by the $\boldsymbol{P}_{1}$ in Step 4), and repeat the above steps until the certain factors of proposition neurons do not change. That is $\boldsymbol{P}_{t}=\boldsymbol{P}_{t-1}$, and export $\boldsymbol{P}_{t}$. Here $t$ is iteration time.

\section{Fault Diagnosis Model and Application Example}

In this paper, three types of fault diagnosis model including line, bus and transformer are mainly considered. Symbol conventions are as follows: $B, L, C B$ and $T$ represents bus, line, circuit breaker and transformer respectively. As to $L_{x y}$, its first subscript $s$ and $r$ represent the sending and receiving terminals respectively, and the second subscript $m, p$ and $s$ represent main, first backup and second backup protective relays respectively. The fault diagnosis model based on AFSN P systems is shown in 
Fig.3. More details about fault diagnosis model can be found in Ref.[13].

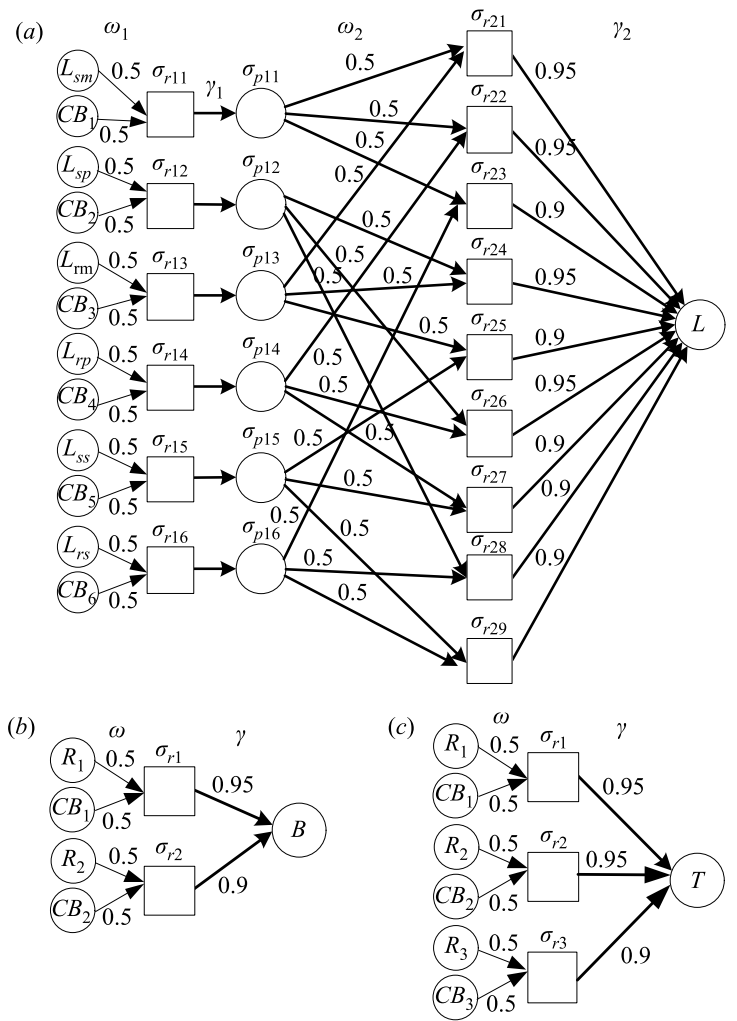

Fig. 3. The fault diagnosis models based on AFSN P systems. (a) Line; (b) Bus; (c) Transformer

The process of fault diagnosis is as follows: Firstly, search the passive regions by using the method of wiring analysis. Then the fault elements will be in the passive regions. Secondly, build the corresponding fault diagnosis models and determine the certain values of operated protective relays and tripped circuit breakers. Thirdly, acquire the fault probability of element through matrix reasoning algorithm based on AFSN P systems. Therefore, the fault elements can be judged via the fault probability of element. Furthermore, to confirm the validity of this approach, an application example of fault diagnosis of power systems is provided. Simultaneously, the diagnosis results are compared with Refs.[16,17]. The sketch map of protective relay system of power system ${ }^{[5]}$ is shown in Fig.4, in which 28 system elements, 84 protective relays and 40 circuit breakers are included. The parameters such as $\lambda, \tau, \omega, \gamma$ are set as Ref.[13]. If the fuzzy truth of element value is over 0.4 , it will be fault element. In this paper, we consider function $f_{\alpha}(x)=e^{-4.5(x-1)^{2}}$. The certain value of the operated protective relays and tripped circuit breakers is as same as Ref.[13]. They are shown in Table 1 and Table 2 .

Thirteen kinds of detected information of protective relays and circuit breakers are used to verify the validity of the proposed method. The diagnosis results are shown in Table 3.

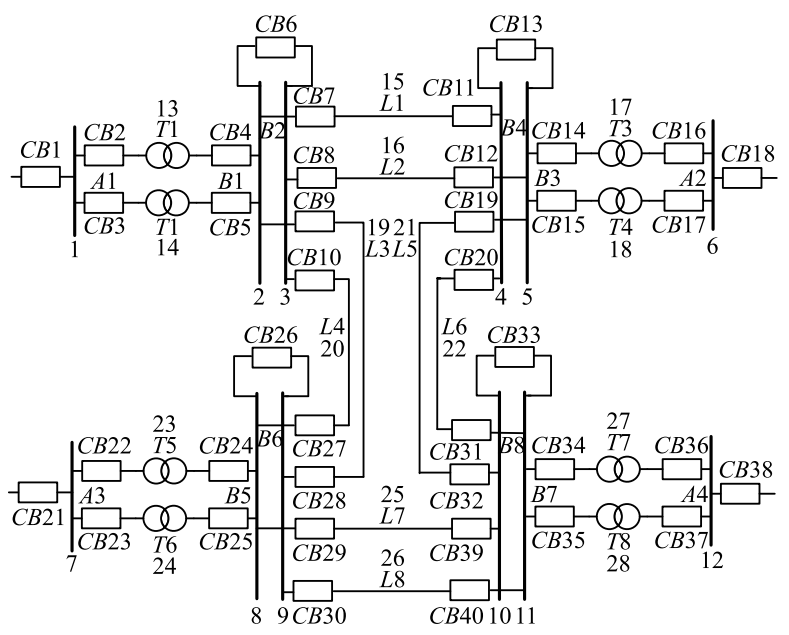

Fig. 4. A sketch map of protective relay system of power system

Table 1. The certain value of the operated protective relays and tripped circuit breakers

\begin{tabular}{|c|c|c|c|c|c|c|}
\hline \multirow{2}{*}{ Element } & \multicolumn{2}{|c|}{$\begin{array}{c}\text { Main protective } \\
\text { relays }\end{array}$} & \multicolumn{2}{c|}{$\begin{array}{c}\text { First backup } \\
\text { protective relays }\end{array}$} & \multicolumn{2}{c|}{$\begin{array}{c}\text { Second backup } \\
\text { protective relays }\end{array}$} \\
\cline { 2 - 7 } & $\begin{array}{c}\text { Protective } \\
\text { relays }\end{array}$ & $\begin{array}{c}\text { Circuit } \\
\text { breakers }\end{array}$ & $\begin{array}{c}\text { Protective } \\
\text { relays }\end{array}$ & $\begin{array}{c}\text { Circuit } \\
\text { breakers }\end{array}$ & $\begin{array}{c}\text { Protective } \\
\text { relays }\end{array}$ & $\begin{array}{c}\text { Circuit } \\
\text { breakers }\end{array}$ \\
\hline Line & 0.9913 & 0.9833 & 0.8 & 0.85 & 0.7 & 0.75 \\
\hline Bus & 0.8564 & 0.9833 & - & - & 0.7 & 0.75 \\
\hline $\begin{array}{l}\text { Trans- } \\
\text { former }\end{array}$ & 0.7756 & 0.9833 & 0.75 & 0.8 & 0.7 & 0.75 \\
\hline
\end{tabular}

Table 2. The certain value of the not operated protective relays and tripped circuit breakers

\begin{tabular}{|c|c|c|c|c|c|c|}
\hline \multirow{2}{*}{ Element } & \multicolumn{2}{|c|}{$\begin{array}{c}\text { Main protective } \\
\text { relays }\end{array}$} & \multicolumn{2}{c|}{$\begin{array}{c}\text { First backup } \\
\text { protective relays }\end{array}$} & \multicolumn{2}{c|}{$\begin{array}{c}\text { Second backup } \\
\text { protective relays }\end{array}$} \\
\cline { 2 - 7 } & $\begin{array}{c}\text { Protective } \\
\text { relays }\end{array}$ & $\begin{array}{c}\text { Circuit } \\
\text { breakers }\end{array}$ & $\begin{array}{c}\text { Protective } \\
\text { relays }\end{array}$ & $\begin{array}{c}\text { Circuit } \\
\text { breakers }\end{array}$ & $\begin{array}{c}\text { Protective } \\
\text { relays }\end{array}$ & $\begin{array}{c}\text { Circuit } \\
\text { breakers }\end{array}$ \\
\hline Line & 0.2 & 0.2 & 0.2 & 0.2 & 0.2 & 0.2 \\
\hline Bus & 0.4 & 0.2 & - & - & 0.4 & 0.2 \\
\hline $\begin{array}{c}\text { Trans- } \\
\text { former }\end{array}$ & 0.4 & 0.2 & 0.4 & 0.2 & 0.4 & 0.2 \\
\hline
\end{tabular}

1) Case 1 to Case 8 in Table 3 are the situation assuming the provided protective information is complete, and incorrect operation and rejecting act of protective relays and circuit breakers are existed. Diagnosis results indicate that the diagnosis elements, incorrect operation and rejecting act can be judged accurately by the proposed method. Therefore, this method has well tolerance when incorrect operation and rejecting act in power system occur.

2) Case 9 to Case 12 are the situation assuming the information provided by SCADA system is incomplete. Diagnosis results show that the proposed method also has well tolerance for this state.

3) Case 13 is the situation assuming the information provided by SCADA system is incomplete. Simultaneously, superfluous information is offered. In this case, the proposed method is also effective.

In summary, in the case of complete, incomplete and superfluous information, the proposed method can diagnose the fault elements exactly because of the well 
Table 3. Fault diagnosis results

\begin{tabular}{|c|c|c|c|c|c|c|c|}
\hline No. & $\begin{array}{l}\text { Action message of } \\
\text { protective relays } \\
\text { and circuit breakers }\end{array}$ & $\begin{array}{l}\text { Missing } \\
\text { message }\end{array}$ & $\begin{array}{c}\text { Diagnosis } \\
\text { results }\end{array}$ & $\begin{array}{c}\text { Probability } \\
\text { of fault }\end{array}$ & $\begin{array}{l}\text { Judgment of } \\
\text { incorrect operation } \\
\text { and rejecting act }\end{array}$ & \begin{tabular}{|c|}
$\begin{array}{l}\text { Diagnosis } \\
\text { results of } \\
\text { Ref.[16] }\end{array}$ \\
\end{tabular} & $\begin{array}{l}\text { Diagnosis } \\
\text { results of } \\
\text { Ref.[17] }\end{array}$ \\
\hline 1 & $\begin{array}{l}\text { Operated protective relays: } \\
\qquad B_{1 m}, L_{2 r s}, L_{4 r s} \\
\text { Tripped circuit breakers: } C B_{4} \\
C B_{5}, C B_{7}, C B_{9}, C B_{12}, C B_{27}\end{array}$ & No & $\begin{array}{l}B_{1} \\
B_{2} \\
L_{2} \\
L_{4}\end{array}$ & $\begin{array}{l}0.82280 \\
0.19604 \\
0.08741 \\
0.12310\end{array}$ & $\begin{array}{c}C B_{6} \text { is rejecting } \\
\text { act }\end{array}$ & $B_{1}: 0.703$ & $\begin{array}{l}B_{1}: 0.999972 \\
B_{2}: 0.00003\end{array}$ \\
\hline 2 & $\begin{array}{l}\text { Operated protective relays: } \\
\quad B_{1 m}, L_{1 s p}, L_{1 r m} \\
\text { Tripped circuit breakers: } C B_{4} \\
C B_{5}, C B_{6}, C B_{7}, C B_{9}, C B_{11}\end{array}$ & No & $\begin{array}{l}B_{1} \\
L_{1}\end{array}$ & $\begin{array}{l}0.92293 \\
0.93226\end{array}$ & $\begin{array}{c}L_{1 s m} \text { is rejecting } \\
\text { act }\end{array}$ & $\begin{array}{l}B_{1}: 0.967 \\
L_{1}: 0.972\end{array}$ & - \\
\hline 3 & $\begin{array}{c}\text { Operated protective relays: } \\
B_{1 m}, B_{2 m}, L_{1 s m}, L_{1 r p}, L_{2 s p}, L_{2 r m} \\
\text { Tripped circuit breakers: } C B_{4}, C B_{5} \\
C B_{6}, C B_{7}, C B_{8}, C B_{9}, C B_{10}, C B_{11}, C B_{12}\end{array}$ & No & $\begin{array}{l}B_{1} \\
B_{2} \\
L_{1} \\
L_{2}\end{array}$ & $\begin{array}{l}0.92293 \\
0.92293 \\
0.93226 \\
0.93226\end{array}$ & $\begin{array}{l}L_{1 r m}, L_{2 s m} \text { are } \\
\text { rejecting act }\end{array}$ & $\begin{array}{l}B_{1}: 0.967 \\
B_{2}: 0.985 \\
L_{1}: 0.972 \\
L_{2}: 0.972\end{array}$ & - \\
\hline 4 & $\begin{array}{c}\text { Operated protective relays: } T_{3 p}, L_{7 s p}, L_{7 r p} \\
\text { Tripped circuit breakers: } C B_{14} \\
C B_{16}, C B_{29}, C B_{39}\end{array}$ & No & $\begin{array}{l}T_{3} \\
L_{7}\end{array}$ & $\begin{array}{l}0.75646 \\
0.88172\end{array}$ & $\begin{array}{l}T_{3 m}, L_{7 s m}, L_{7 r m} \\
\text { are rejecting act }\end{array}$ & $\begin{array}{l}T_{3}: 0.938 \\
L_{7}: 0.938\end{array}$ & - \\
\hline 5 & $\begin{array}{c}\text { Operated protective relays: } T_{5 s}, T_{6 s} \\
\text { Tripped circuit breakers: } C B_{22}, \\
\qquad B_{23}, C B_{24}, C B_{25}\end{array}$ & No & $A_{3}$ & 0.64039 & $\begin{array}{l}A_{3 m} \text { is rejecting act, } \\
\quad C B_{24}, C B_{25} \text { are } \\
\text { incorrect operation }\end{array}$ & $A_{3}: 0.648$ & $A_{3}: 0.833151$ \\
\hline 6 & $\begin{array}{c}\text { Operated protective relays: } \\
T_{7 m}, T_{8 p}, B_{7 m}, B_{8 m} \\
L_{5 s m}, L_{5 r p}, L_{6 s s} \\
L_{7 s p}, L_{7 r m}, L_{8 s s} \\
\text { Tripped circuit breakers: } \\
C B_{19}, C B_{20}, C B_{29}, C B_{30} \\
C B_{32}, C B_{33}, C B_{34}, C B_{35} \\
C B_{36}, C B_{37}, C B_{39}\end{array}$ & No & $\begin{array}{l}L_{5} \\
L_{6} \\
L_{7} \\
L_{8} \\
B_{7} \\
B_{8} \\
T_{7} \\
T_{8}\end{array}$ & $\begin{array}{l}0.93226 \\
0.15931 \\
0.93226 \\
0.15931 \\
0.78911 \\
0.78911 \\
0.88986 \\
0.71665\end{array}$ & $\begin{array}{l}L_{5 r m}, L_{7 s m}, T_{8 m} \\
C B_{31}, C B_{40} \text { are } \\
\quad \text { rejecting act }\end{array}$ & $\begin{array}{c}L_{5}: 0.972 \\
L_{7}: 0.972 \\
L_{8}: 0.693 \\
B_{7}: 0.703 \\
B_{8}: 0.985 \\
T_{7}: 0.99 \\
T_{8}: 0.938\end{array}$ & - \\
\hline 7 & $\begin{array}{l}\text { Operated protective relays: } L_{1 s m}, L_{1 r p} \\
L_{2 s p}, L_{2 r p}, L_{7 s p}, L_{7 r m}, L_{8 s m}, L_{8 r m} \\
\text { Tripped circuit breakers: } C B_{7}, C B_{8} \\
C B_{11}, C B_{12}, C B_{29}, C B_{30}, C B_{39}, C B_{40}\end{array}$ & No & $\begin{array}{l}L_{1} \\
L_{2} \\
L_{7} \\
L_{8}\end{array}$ & $\begin{array}{l}0.93226 \\
0.88172 \\
0.93226 \\
0.94999\end{array}$ & $\begin{array}{c}L_{1 r m}, L_{2 s m} \\
\quad L_{2 r m}, L_{7 s m} \\
\text { are rejecting act }\end{array}$ & $\begin{array}{c}L_{1}: 0.972 \\
L_{2}: 0.938 \\
L_{7}: 0.972 \\
L_{8}: 0.99\end{array}$ & - \\
\hline 8 & $\begin{array}{c}\text { Operated protective relays: } \\
B_{1 m}, T_{1 m}, T_{2 m}, L_{1 s m}, L_{1 r p} \\
\text { Tripped circuit breakers: } C B_{2} \\
C B_{3}, C B_{4}, C B_{5}, C B_{6} \\
C B_{7}, C B_{9}, C B_{11}\end{array}$ & No & $\begin{array}{l}B_{1} \\
T_{1} \\
T_{2} \\
L_{1}\end{array}$ & $\begin{array}{l}0.92293 \\
0.88986 \\
0.88986 \\
0.93226\end{array}$ & $\begin{array}{l}L_{1 \mathrm{rm}} \text { is } \\
\text { rejecting act }\end{array}$ & - & $\begin{array}{l}B_{1}: 0.941542 \\
T_{1}: 0.751081 \\
T_{2}: 0.751081 \\
L_{1}: 0.999175 \\
L_{2}: 0.000043\end{array}$ \\
\hline 9 & $\begin{array}{c}\text { Operated protective relays: } \\
\qquad B_{1 m}, L_{4 r s} \\
\text { Tripped circuit breakers: } \\
C B_{4}, C B_{7}, C B_{9}, C B_{12}, C B_{27}\end{array}$ & $\begin{array}{l}L_{2 r s}, C B_{5} \\
\text { in Case } 1 \\
\text { are missing }\end{array}$ & $\begin{array}{l}B_{1} \\
B_{2} \\
L_{2} \\
L_{4}\end{array}$ & $\begin{array}{l}0.67294 \\
0.06962 \\
0.08741 \\
0.12310\end{array}$ & $\begin{array}{c}C B_{6} \text { is rejecting } \\
\text { act }\end{array}$ & - & $\begin{array}{c}B_{1}: 0.999986 \\
B_{2}: 0.00003\end{array}$ \\
\hline 10 & $\begin{array}{c}\text { Operated protective relays: } T_{3 p}, L_{7 r p} \\
\text { Tripped circuit breakers: } \\
C B_{14}, C B_{16}, C B_{29}, C B_{39}\end{array}$ & $\begin{array}{l}L_{7 s p} \text { in Case } 4 \\
\text { is missing }\end{array}$ & $\begin{array}{l}T_{3} \\
L_{7}\end{array}$ & $\begin{array}{l}0.58495 \\
0.88172\end{array}$ & $\begin{array}{l}T_{3 m}, L_{7 \mathrm{sm}}, L_{7 \mathrm{rm}} \\
\text { are rejecting act }\end{array}$ & - & - \\
\hline 11 & $\begin{array}{c}\text { Operated protective relays: } \\
T_{8 p}, B_{7 m}, B_{8 m}, L_{5 r p} \\
L_{6 s s}, L_{7 s p}, L_{7 r m} \\
\text { Tripped circuit breakers: } \\
C B_{19}, C B_{20}, C B_{29}, C B_{30} \\
C B_{32}, C B_{33}, C B_{34} \\
C B_{35}, C B_{36}, C B_{37}, C B_{39}\end{array}$ & $\begin{array}{l}T_{7 m}, L_{5 s m}, L_{8 s s} \\
\quad \text { in Case } 6 \\
\text { are missing }\end{array}$ & $\begin{array}{l}L_{5} \\
L_{6} \\
L_{7} \\
L_{8} \\
B_{7} \\
B_{8} \\
T_{7} \\
T_{8}\end{array}$ & $\begin{array}{l}0.58495 \\
0.15931 \\
0.93226 \\
0.15931 \\
0.78911 \\
0.78911 \\
0.61931 \\
0.71665 \\
\end{array}$ & $\begin{array}{c}\quad L_{5 r m}, L_{7 s m} \\
T_{8 m}, C B_{31}, C B_{40} \\
\text { are rejecting act }\end{array}$ & - & - \\
\hline 12 & $\begin{array}{c}\text { Operated protective relays: } \\
B_{1 m}, T_{2 m}, L_{1 s m}, L_{1 r p} \\
\text { Tripped circuit breakers } \\
C B_{2}, C B_{3}, C B_{4}, C B_{5} \\
C B_{7}, C B_{9}, C B_{11} \\
\end{array}$ & $\begin{array}{l}T_{1 m}, C B_{6} \\
\text { in Case } 8 \\
\text { are missing }\end{array}$ & $\begin{array}{l}B_{1} \\
T_{1} \\
T_{2} \\
L_{1}\end{array}$ & $\begin{array}{l}0.82313 \\
0.61931 \\
0.88986 \\
0.93226\end{array}$ & $\begin{array}{c}L_{1 r m} \text { is rejecting } \\
\text { act }\end{array}$ & - & $\begin{array}{l}B_{1}: 0.941384 \\
T_{1}: 0.312753 \\
T_{2}: 0.751081 \\
L_{1}: 0.999175 \\
L_{2}: 0.000043 \\
\end{array}$ \\
\hline 13 & $\begin{array}{l}\text { Operated protective relays: } \\
\quad B_{2 m}, L_{2 r s}, L_{4 r s} \\
\text { Tripped circuit breakers: } C B_{4} \text {, } \\
C B_{5}, C B_{7}, C B_{9}, C B_{12}, C B_{27}\end{array}$ & $\begin{array}{c}B_{1 m} \text { in Case } 1 \\
\text { is missing, } \\
B_{2 m} \text { is superfluous }\end{array}$ & $\begin{array}{l}B_{1} \\
B_{2} \\
L_{2} \\
L_{4}\end{array}$ & $\begin{array}{c}0.45134 \\
0.3489 \\
0.08741 \\
0.12310 \\
\end{array}$ & $\begin{array}{c}C B_{6} \text { is rejecting } \\
\text { act }\end{array}$ & - & - \\
\hline
\end{tabular}


tolerance. In the meantime, comparative diagnosis results using three different methods are shown in Table 4 . The results under the situation of Case 1 to Case 9 and under Case 12 are the basically same as in Ref.[16] and Ref.[17]. However, under the situation of Case 6 , the fault probability of $L_{8}$ is 0.15931 using the proposed method, and $L_{8}$ is judged to be no fault. However, $L_{8}$ is judged to be fault in Ref.[16] because the fault probability of $L_{8}$ is 0.693 . Actually, the second backup protective relays $L_{8 s s}$ operate as the second backup protective relays of $B_{7}$, while $L_{8}$ do not malfunction. Consequently, the diagnosis result of the proposed method is right, while the result of Ref.[16] is wrong. Although the Ref.[17] can make correct diagnosis for all cases, it will need to re-modeling and re-training for different elements and different grids. Thence, the diagnostic process of Ref.[17] is more complex relatively. Here, performance comparison of three methods including this method and of Refs. $[16,17]$ is shown in Table 4.

Table 4. Performance comparison of different methods

\begin{tabular}{|c|c|c|c|}
\hline Method & $\begin{array}{c}\text { Degree of } \\
\text { computation }\end{array}$ & $\begin{array}{c}\text { Accurate of } \\
\text { diagnosis results }\end{array}$ & $\begin{array}{c}\text { Capacity of the } \\
\text { grid topology }\end{array}$ \\
\hline $\begin{array}{c}\text { The } \\
\text { proposed } \\
\text { method }\end{array}$ & $\begin{array}{c}\text { Fast computing } \\
\text { rate because of } \\
\text { matrix } \\
\text { representation }\end{array}$ & $\begin{array}{c}\text { Every case in } \\
\text { Table } 3 \text { can obtain } \\
\text { a correct result }\end{array}$ & $\begin{array}{c}\text { Not need to re- } \\
\text { modeling, so has } \\
\text { good capacity of } \\
\text { the grid topology }\end{array}$ \\
\hline $\begin{array}{c}\text { The } \\
\text { method } \\
\text { of } \\
\text { Ref.[16] }\end{array}$ & $\begin{array}{c}\text { Can be } \\
\text { expressed by } \\
\text { matrix }\end{array}$ & $\begin{array}{c}\text { Case } 9 \text { to Case } 12 \\
\text { in Table } 3 \text { can not } \\
\text { get the correct } \\
\text { results, and result of } \\
\text { the Case } 6 \text { is wrong }\end{array}$ & $\begin{array}{c}\text { Need to } \\
\text { re-modeling }\end{array}$ \\
\hline $\begin{array}{c}\text { The } \\
\text { method } \\
\text { of } \\
\text { Ref.[17] }\end{array}$ & $\begin{array}{c}\text { Formula } \\
\text { reasoning } \\
\text { of Bayesian }\end{array}$ & $\begin{array}{c}\text { Every case in } \\
\text { Table } 3 \text { can } \\
\text { obtain a correct } \\
\text { result }\end{array}$ & $\begin{array}{c}\text { Need to } \\
\text { re-modeling } \\
\text { and re-training }\end{array}$ \\
\hline
\end{tabular}

\section{Learning Ability of AFSN P Systems Using PSO Algorithm}

The learning ability to adjust automatically is another performance of AFSN P systems. Weights of AFSN P systems can be trained by imitating the learning algorithm of neural networks. Thus the diagnosis results are more close to actual situation. Here, fault diagnosis model of bus based on AFSN P systems shown in Fig.5 is used as an example to train the weights.

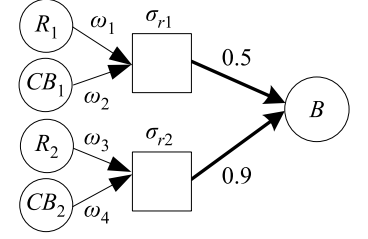

Fig. 5. Fault diagnosis model of bus based on AFSN $\mathrm{P}$ systems

\section{Error back propagation algorithm of AFSN} P systems

In our paper, the learning algorithm of AFSN P systems adopts the idea of error back propagation algorithm of BP neural networks. The detail step of the proposed algorithm is as follows.

1) Initialize the weights.
2) The training samples include input samples and the desired output samples. Input samples are the certain values of operated protective relays and tripped circuit breakers when bus is failure. Desired output samples are determined artificially. All training data is shown in Table 5 .

3) Calculate the actual output samples. According to the specific structure of AFSN P systems, the actual output samples can be acquired by the fuzzy reasoning algorithm.

4) Adjust the weights. After calculating the difference between current actual output and the desired output, the weights will be updated by the error back propagation algorithm of AFSN P systems until the difference between current actual output and the desired output meet error requirements. The weight updating representations of error back propagation algorithm is as follows.

$$
\begin{gathered}
\omega(t+1)=\omega(t)+\eta f_{\alpha}^{\prime}(x) e(t) x(t) \\
E(t)=y^{*}(t)-y(t) \\
f_{\alpha}(x)=e^{-4.5(x-1)^{2}}
\end{gathered}
$$

where $t$ is iteration number. $\omega(t)$ is weight while iteration number is $t . \eta$ is learning rate. $f_{\alpha}(x)$ is transfer function. $E(t)$ is differentials. $x(t)$ is input samples. $y^{*}(t)$ is the desired output samples. $y(t)$ is current actual output samples while iteration number is $t$.

Table 5. Training data

\begin{tabular}{|c|c|c|c|}
\hline No. & Input samples & $\begin{array}{c}\text { Initial output } \\
\text { sample }\end{array}$ & $\begin{array}{c}\text { Initial output } \\
\text { sample }\end{array}$ \\
\hline 1 & $0.8564,0.9913,0.4,0.2499$ & 0.9255 & 1 \\
\hline 2 & $0.8564,0.6555,0.42,0.45$ & 0.7266 & 0.8 \\
\hline 3 & $0.8564,0.3277,0.56,0.6$ & 0.4492 & 0.5 \\
\hline 4 & $0.8564,0.7375,0.28,0.3$ & 0.7891 & 0.85 \\
\hline 5 & $0.8564,0.49165,0.42,0.45$ & 0.5889 & 0.65 \\
\hline 6 & $0.4,0.3277,0.4,0.2499$ & 0.1538 & 0.1 \\
\hline 7 & $0.4,0.2458,0.4,0.2499$ & 0.1207 & 0.1 \\
\hline 8 & $0.4,0.3277,0.175,0.1875$ & 0.1538 & 0.1 \\
\hline
\end{tabular}

Fig.6(a), Fig.6(b) and Fig.6(c) show three different training processes with weight $\omega_{1}$, weight $\omega_{2}$ and mean square error $e$ respectively. When the iteration is around 500, two weights converge to $\omega_{1}=0.5221, \omega_{2}=0.5258$, and error converge to $e=0.00177$. Therefore, the diagnosis results are more close to actual situation via utilizing the error back propagation algorithm of AFSN P systems. Back propagation algorithm of AFSN P systems has the problems that low learning efficiency and slow convergence speed.

2. Learning algorithm of AFSN $P$ systems based on PSO

In this paper, Particle swarm optimization (PSO) algorithm ${ }^{[18]}$ is applied to optimize the learning algorithm of AFSN P systems. The thought of this new method is based on the back propagation algorithm and the initial 

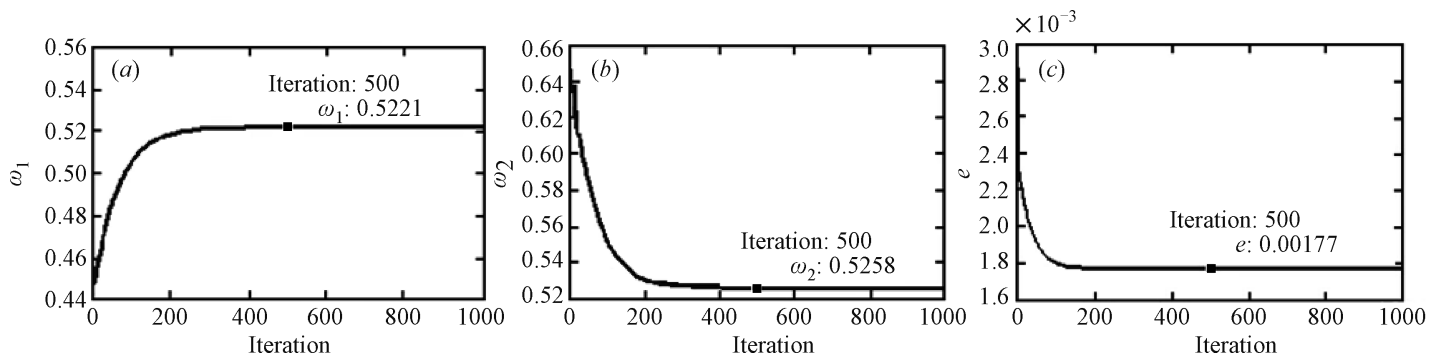

Fig. 6. The learning results: $(a) \omega_{1} ;(b) \omega_{2} ;(c) e$

weights of AFSN P systems are optimized by PSO so that the convergence can be obtained fast and accurately. The dimension of particle is the number of weights that need to update. Each particle is a solution of weights of AFSN $\mathrm{P}$ systems. The best initial weights which own the best fitness are acquired by the particle optimization. The fitness of particle is the mean square error. Specific algorithm process is as follows.

1) Initialize a set of particle swarm.

2) The mean square error obtained by learning algorithm of AFSN P systems in Section IV.1 is acted as fitness of particle.

3) The particle with best fitness which is the optimal initial weight can be acquired by evolution mechanism of PSO algorithm.

4) Take the weights training as Section IV.1, but the weight in Step 1) of Section IV.1 is replaced by the optimal initial weight in Step 3) of this subsection.

These two algorithms are applied to fault diagnosis respectively. 20 times tests are carried on the two algorithms and the results shown in Table 6 . The comparison parameters are the iteration numbers of weights and mean square error reach to converge, and the iteration number is fewer, the convergence speed is faster and the efficiency is higher. The best, worst and mean convergence curves of the two algorithms in 20 times tests are compared in Fig.7.

In the 20 times tests, the best result of error back propagation algorithm of AFSN P systems is iteration number $t=95$. Nevertheless, the best result of learning algorithm of AFSN P systems based on PSO algorithm is iteration number $t=4$. Seen from Table 6 and Fig.7, the convergence speed of learning algorithm of AFSN P sys- tems based on particle swarm optimization is faster than error back propagation algorithm of AFSN P systems obviously. Therefore, the introduction of PSO algorithm has substantially improved the learning efficiency of AFSN P systems.

Table 6. Comparison of the two learning algorithms

\begin{tabular}{|c|c|c|c|c|c|c|}
\hline & \multicolumn{3}{|c|}{$\begin{array}{c}\text { Error back } \\
\text { Algorithm }\end{array}$} & \multicolumn{3}{c|}{$\begin{array}{c}\text { Learning algorithm of } \\
\text { propagation algorithm } \\
\text { of AFSN P systems } \\
\text { on particle swarm } \\
\text { optimization }\end{array}$} \\
\hline $\begin{array}{c}\text { Comparison } \\
\text { parameters }\end{array}$ & $\omega_{1}$ & $\omega_{2}$ & $e$ & $\omega_{1}$ & $\omega_{2}$ & $e$ \\
\hline 1 & 491 & 570 & 248 & 97 & 176 & 6 \\
\hline 2 & 516 & 504 & 252 & 129 & 118 & 5 \\
\hline 3 & 473 & 551 & 230 & 5 & 6 & 5 \\
\hline 4 & 542 & 621 & 299 & 102 & 181 & 5 \\
\hline 5 & 351 & 429 & 108 & 158 & 146 & 8 \\
\hline 6 & 454 & 532 & 211 & 82 & 160 & 6 \\
\hline 7 & 523 & 511 & 259 & 74 & 152 & 7 \\
\hline 8 & 420 & 408 & 156 & 5 & 4 & 4 \\
\hline 9 & 491 & 479 & 228 & 5 & 5 & 4 \\
\hline 10 & 338 & 417 & 95 & 8 & 67 & 7 \\
\hline 11 & 388 & 376 & 124 & 59 & 138 & 6 \\
\hline 12 & 438 & 427 & 175 & 125 & 203 & 4 \\
\hline 13 & 379 & 367 & 115 & 7 & 7 & 6 \\
\hline 14 & 468 & 456 & 204 & 11 & 9 & 9 \\
\hline 15 & 481 & 559 & 238 & 128 & 117 & 4 \\
\hline 16 & 509 & 497 & 246 & 38 & 26 & 4 \\
\hline 17 & 397 & 385 & 133 & 66 & 55 & 4 \\
\hline 18 & 463 & 542 & 220 & 168 & 156 & 6 \\
\hline 19 & 482 & 561 & 239 & 87 & 165 & 8 \\
\hline 20 & 491 & 570 & 248 & 7 & 8 & 6 \\
\hline & & & & & & \\
\hline
\end{tabular}

\section{Conclusion}

The improved AFSN P systems are applied to fault diagnosis of power systems successfully in this paper. The
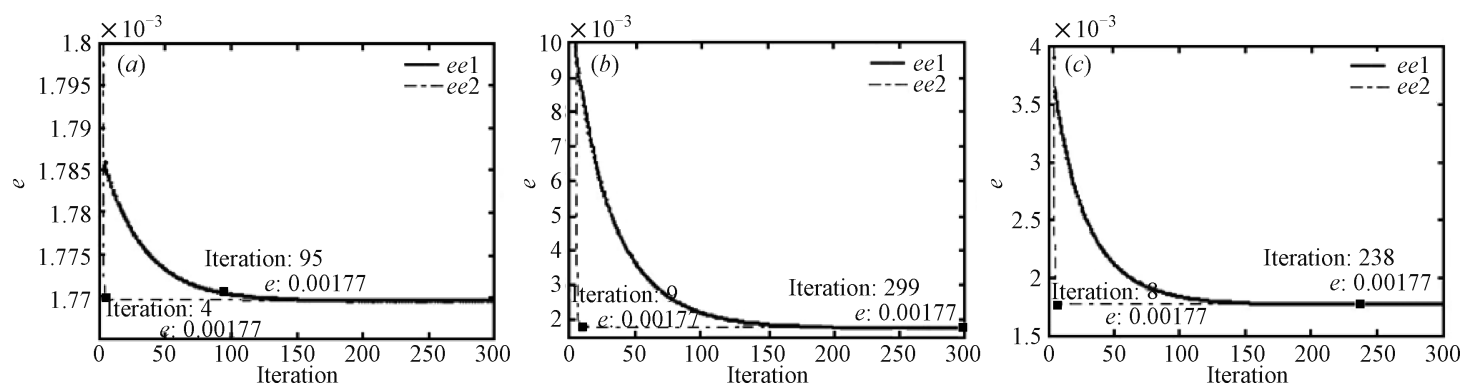

Fig. 7. Convergence curve of the two algorithms. (a) The best; (b) The worst; $(c)$ The mean 
situations of complete, incomplete and superfluous information under SCADA system are analyzed respectively. Diagnosis results show that the proposed method can accurately diagnose fault elements, judge incorrect operation and rejecting act. Furthermore, compared with other methods, the diagnosis process can be expressed more intuitively and simple using matrix so that diagnosis speed is faster. The diagnosis precision is higher through introducing transfer function into the initial rule neurons of AFSN P systems. In the meantime, the proposed method has better capacity of the grid topology because it is not need to re-modeling. The convergence speed in this paper is improved obviously after PSO algorithm is successfully leaded into learning algorithm of AFSN P systems. Our future work will focus on training the weights of line and bus. We also want to investigate the application of AFSN $\mathrm{P}$ systems in fault diagnosis of transformer and diesel engine.

\section{References}

[1] V.M. Ernesto, L. Oscar, M. Chacon, et al., "An on-line expert system for fault section diagnosis in power systems", IEEE Transactions on Power Systems, Vol.12, No.1, pp.357-362, 1997.

[2] G.J. Cheng and W.M. Li, "Expert system based on neural network for ICCAT", Acta Electronica Sinica, Vol.22, No.8, pp.2428, 1994. (in Chinese)

[3] T.S. Bi, Y.X. Ni, F.L. Wu, et al., "A novel neural network approach for fault section estimation", Proceedings of the Chinese Society for Electrical Engineering, Vol.22, No.2, pp.73-78, 2002. (in Chinese)

[4] D.Q. Zhu and Q.B. Sang, "A fault diagnosis algorithm for the photovoltaic radar electronic equipment based on quantum neural networks", Acta Electronica Sinica, Vol.34, No.3, pp.573576, 2006. (in Chinese)

[5] X.N. Lin, S.H. Ke, Z.T. Li, et al., "A fault diagnosis method of power systems based on improved objective function and genetic algorithm-tabu search", IEEE Transactions on Power Delivery, Vol.25, No.3, pp.1268-1274, 2010.

[6] H.C. Chin, "Fault section diagnosis of power system using fuzzy logic", IEEE Transactions on Power Systems, Vol.18, No.1, pp.245-250, 2003.

[7] G.X. Zhang and L.Q. Pan, "A survey of membrane computing as a new branch of natural computing", Chinese Journal of Computers, Vol.33, No.2, pp.208-214, 2010. (in Chinese)

[8] L. Huang, I. Hong Suh and A. Abraham, "Dynamic multiobjective optimization based on membrane computing for control of time-varying unstable plants", Information Sciences, Vol.181, No.11, pp.2370-2391, 2011.

[9] G.X. Zhang, J.X. Cheng, M. Gheorghe, et al., "A hybrid approach based on differential evolution and tissue membrane systems for solving constrained manufacturing parameter optimization problems", Applied Soft Computing, Vol.13, No.3, pp.1528-1542, 2013.

[10] J. Wang, L. Zhou, H. Peng, et al., "An extended spiking neural P system for fuzzy knowledge representation", International Journal of Innovative Computing, Information and Control, Vol.7, No.7A, pp.3709-3724, 2011.
[11] J. Wang, P. Shi, H. Peng, et al., "Weighted fuzzy spiking neural P systems", IEEE Transactions on Fuzzy Systems, Vol.21, No.2, pp.209-220, 2013.

[12] H. Peng, J. Wang, M.J. Pérez-Jiménez, et al., "Fuzzy reasoning spiking neural P system for fault diagnosis", Information Sciences, Vol.235, No.20, pp.106-116, 2013.

[13] M. Tu, J. Wang, H. Peng, et al., "Application of adaptive fuzzy spiking neural P systems in fault diagnosis of power systems", Chinese Journal of Electronics, Vol.23, No.1, pp.87-92, 2014.

[14] X.X. Zeng, H. Adorna, M.Á. Martínez-del-Amorr, et al., "Matrix representation of spiking neural $\mathrm{P}$ systems", 11th International Conference, CMC2010, Jena, Germany, pp.377-391, 2011.

[15] J. Wang and H. Peng, "Adaptive fuzzy spiking neural P systems for fuzzy inference and learning", International Journal of Computer Mathematics, Vol.90, No.4, pp.857-868, 2013.

[16] J. Sun, S.Y. Qing and Y.H. Song, "Fuzzy petri nets and its application in the fault diagnosis of electric power systems", Proceedings of the Chinese Society for Electrical Engineering, Vol.24, No.9, pp.74-79, 2004. (in Chinese)

[17] X. Wu and C.X. Guo, "Power system fault diagnosis approach based on bayesian network", Proceedings of the CSU - EPSA, Vol.17, No.4, pp.11-15, 2005. (in Chinese)

[18] X.J. Wu, Z.Z. Yang and M. Zhao, "A uniform searching particle swarm optimization algorithm", Acta Electronica Sinica, Vol.39, No.6, pp.1261-1266, 2011. (in Chinese)

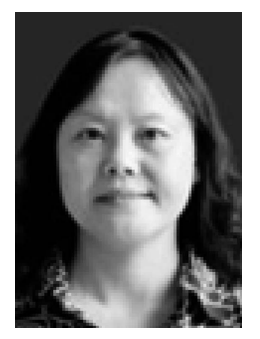

WANG Jun is a professor of the School of Electrical and Information Engineering, Xihua University, China. Her major research interests include electrical automation, intelligent control, and membrane computing. (Email: 745257101@qq.com)

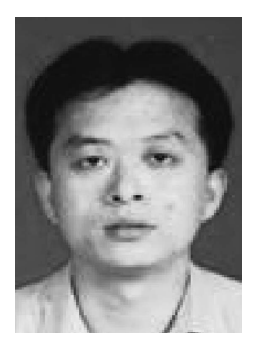

PENG Hong is a professor of the Center for Radio Administration and Technology Development, Xihua University, China. His research interests include membrane computing, digital watermarking, image processing, signal processing and kernel methods.

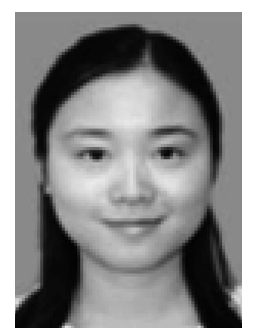

TU Min is a staff of the Neijiang Power Supply Company, China. Her research interests include the membrane computing and its application in fault diagnosis and economic load dispatch of power systems.

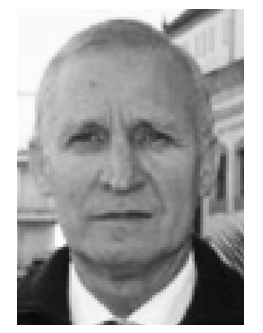

Pérez-Jiménez J. Mario is a member of the Academia Europaea, and a full professor in the Department of Computer Science and Artificial Intelligence, University of Seville, Spain. His research interests include theory of computation, computational complexity theory, natural computing, bioinformatics, and computational modelling for systems biology and population biology. 